\title{
Multilevel state policy on the basis of the open model of innovation process management
}

\author{
Elena Akerman ${ }^{\mathrm{a}}$, Oksana Kozlovskaya, Galina Barysheva, Yuliya Burets ${ }^{\mathrm{b}}$ \\ Tomsk Polytechnic University, 30 Lenin Ave., Tomsk, 634050, Russia
}

\begin{abstract}
The paper presents the viewpoint of the authors concerning the concept of state innovation policy on the basis of economic synergy and evolution theoretical propositions. The improvement of approaches to the innovation policy formation is necessitated by the behavior changes in the innovation activity of subjects and by the spreading of the open model of the innovation process management at the microlevel. The paper reveals synergy methodological principles in the context of the innovation policy formation, the significance of every management level from the viewpoint of organization and self-organization processes. The necessity of spatial-level interactions both "subject-object" and "subject-subject" is substantiated.
\end{abstract}

\section{Introduction}

Actualization of network innovation interactions was preceded by a number of objective economic processes: complication of the innovation product and the innovation process, reciprocal enrichment of scientific disciplines and technology fields, territorial specialization, globalization, irregular distribution of various resources and potentials. By the present time many research papers, proving a transition from closed models of the innovation process management at the microlevel to open ones, have been written (e. g., R. Rothwell, A. Horsley, H. Chesbrough, Enkel E., Gassmann O., Lichtenthaler U., Rasmussen B., Herstad S.J., Ebersberger B., Velde E., Teirlinck P., Spithoven A., Trott P., Hartmann D., Vrande V., Jong J., Vanhaverbeke W., Rochemont M., West J., Bogers M., Wit J., Dankbaar B.). Gradually firms stop using a closed innovation process, which occurs entirely in the frame of one firm, and tend to the interaction with external environment.

\section{Open approaches to innovations}

In scientific literature when speaking about interactions of subjects in the innovation activity process it is appropriate to use the term "open innovations". Open innovations are becoming still more important in the discussion of R\&D globalization that assumes higher capital mobility, wide ICT spreading, etc.

According to H. Chesbrough, who was the first to use this term, "open innovations" are a paradigm which

\footnotetext{
a Corresponding author: aker@tomsk.gov.ru

b Corresponding author: buretsys@tomsk.gov.ru
}

implies that firms can and must use external and internal ideas and pathways to the market [1]. In general Chesbrough H.W. formulates the main idea of open innovations in the following way: «open innovations are a purposeful use of knowledge inflow and outflow to accelerate internal innovations and to expand markets for external innovation applications as well [2]. German scientist U. Lichtenthaler describes open innovations as «a process of systematic search and acquisition of external sources of knowledge and technologies, as well as effective application of the knowledge both in the company and in the process of close interactions with external organizations» [3]. There are more general definitions, for example, «it is any form of cooperation with third parties which can promote the improvement of long term activity of the company» [4].

There are many research works of open approaches to innovations. Mowery D. believes that historically the innovation has always been open, but both in the society and industry there were closed periods after which they started their restoration [5]. It was in 1987 when theoretical foundations of the open innovation process were formulated by Swiss economist Strebel P., in particular, he stated that at some stages of the corporation life cycle the innovation process can be encouraged «by the open innovation policy» [6]. In 1992 Mokyr J. recognized the social medium, which is determined by «the openness to new ideas» [5] as a factor of innovation difference among nations. In 1990 Cohen and Levinthal, developing the concept of the taking up capability of the company, suggested that companies arrange the R\&D system not only for the internal innovation management, but for its capability to 
take up external ideas, various types of knowledge as well [7]. In addition, Nelson and Winter also recognize openness to the external medium as a factor of the ability improvement for innovations and necessity to keep contacts with customers, suppliers, etc. in their works (1982).

Accumulation of new characteristics in the innovation process allows us to determine mainstreams of the evolution of models: from a linear character to a nonlinear one and from closed to open; from one source of innovation generation to multiple ones; from succession of process stages to parallelism and feedback formation; from narrow-purpose professionalism of innovation activity specialists to their multi-profile specialization; from division of the functional between stages and work groups to interfunctionality; from rigidity of organization structures to their flexibility and adaptivity; from innovation process detachment to its integration into the general process of organizational strategic management.

\section{The open model of the innovation process management}

Efficiency of the state innovation policy is greatly dependent on the consideration of changes in the behavior of firms at the microlevel (models of innovation process management). The development of the state innovation policy "from below" as a response to new demands of subjects, creating innovations, is studied in the paper. Thus, a theoretical development of an open model of the innovation process management $(5 \mathrm{G})$ in the multilevel aspect is provided.

A joint interaction of innovation activity subjects is a foundation of the open model. The research of joint interaction effects is carried out in the frame of the interdisciplinary scientific trend - synergy. We suppose that main points of economic synergy can be used to develop management of open innovation processes at all levels of economy. As S.P. Kurdjumov points out: «...synergy is a theory of evolution and selforganization of complex systems, which gives general points for research, prediction and modeling of processes, in complex social systems as well» [8].

In Table 1 management peculiarities of open and closed innovation systems (from the viewpoint of main characteristics of the innovation process and management peculiarities in the system) are presented.

Table 1. Management peculiarities of open and closed innovation systems

\begin{tabular}{|c|c|c|}
\hline & Closed Model & Open Model \\
\hline 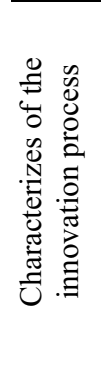 & $\begin{array}{l}\text { Domination of linear } \\
\text { models of innovation } \\
\text { process management in } \\
\text { economy. } \\
\text { R\&D concentration in one } \\
\text { subject (organization, } \\
\text { region). } \\
\text { Strengthening of } \\
\text { competitive advantages } \\
\text { due to temporal monopoly }\end{array}$ & $\begin{array}{l}\text { Domination of nonlinear } \\
\text { models of innovation } \\
\text { process management in } \\
\text { economy. } \\
\text { R\&D distribution } \\
\text { between subjects } \\
\text { (organizations, regions). } \\
\text { Strengthening of } \\
\text { competitive advantages } \\
\text { due to cooperative }\end{array}$ \\
\hline
\end{tabular}

of R\&D.

Resources concentration

synergy effects.

Distribution,

complementarity of resources.

Inflexibility, low-level adaptation to external environment.

High-level adaptation to external environment, dependence. Outstripping

Lagging in technological fields, which do not correspond to «the profile» (specialization). development of «profile» fields and supporting development of nonprofile ones due to external innovation sources.

Considerable temporal lag Shortened temporal lag of the innovation process. of the innovation process. High risks of innovation activity.

A high level of innovation security.

Dominance of individual intellectual property.

An interaction mode of subjects is competitive substitution.

Predicted external environment. Division of innovation activity risks.

Risks and threats of openness.

Dominance of collective intellectual property.

Interaction mode of subjects is competitive addition.

Uncertainty of external environment.

Statistics of systems.

Order, equilibrium

Internal sources of

development.

Organization

System structure, interrelation of elements inside the system.

The main instrument is state financing of the first stages of the innovation process.

«Cloning» of successful structures, advanced experience.

Dynamics of systems. Development, evolution. External and internal development sources. Self-organization, coevolution.

Cooperative processes inside and outside the system.

Creation of institutional environment of interactions, information exchange.

Support of the elements variety, their coevolution.

Synergy research objects, regardless of their nature, must correspond with some requirements: openness, non-equilibrium state, spasmodic way out of the critical state [9]. Non-equilibrium implies an instability state (on the contrary to the orthodox tendency towards equilibrium). According to Moiseev N.N., «stability, having reached its limit, stops any progress ... Too stable forms are deadlock ones, which stop evolution. Too excessive adaptation... is as dangerous for type perfection as inability to adaptation» [10]. In its turn, a spasmodic way out of the critical state allows developing a qualitatively new state of the system with a higher level of order. The system capability to selforganize is of importance, i.e. along with these three mentioned characteristics, nonlinearity (feedback channels, diversity of evolution trends) and dynamism (progress in time, a change of the system elements and relations between them) are required

The up-to date model of the innovation process management ( $5 \mathrm{G}$ - System integration and networks) [11] is an open, non-linear, complex, emergent, 
dynamic, evolving system, capable of accumulating and making use of past experience. Thus, its characteristics correspond to necessary qualities of systems studied in the frame of economic synergy. The development of innovation process management models is phase evolutional transformations. The authors mentioned above confirmed this and turned to foundations of the theory of self-organization and synergy.

The post-industrial society development is characterized by the increase of information environment density that provides business subjects with additional freedom and greater possibilities to organize their activity [12]. This can be regarded as entropic component growth in the system that supports activation of self-organization processes at various economy levels and is revealed in the increase of intersubject network interactions.

From the viewpoint of state innovation policy development it is important to understand how to develop foundations of the open model of the innovation process management at higher economy levels (mezo- and macro-) taking into account their institutional peculiarities and resource possibilities, aggregation level, «subject-object» behaviour. Such a «transfer» validity can be reasoned by the quotation of Yevstigneeva L.P. and Yevstigneev R.N.: «synergy opposes the approach when the subject and the method of macro- and micro- are divided based on the principle: or - or. It is a macroeconomics theory evolved not as a result of cutting off microcosm from macrocosm, but, on the contrary, for the sake of macroeconomics as an integral system, in which micro and macro have a more profound relationship than that resulted from hierarchy, inherent to the centralization system... In economic synergy space a tendency to coincidence of the macroeconomics structure and the content (in its full scope) of specific forms of Objective Reality is observed» [13].

\section{Methodological synergy principles in the context of state innovation policy development on the basis of the open model of innovation process management}

Let us consider main methodological synergy principles in the context of state innovation policy development on the basis of the open model of innovation process management. The main synergy principles are: 1) a stage of stable functioning of the system: homeostatic nature, hierarchical nature; 2) a transformation stage, renewal of a system: nonlinearity, openness, instability, dynamic hierarchical nature, observability [14-16]. In government innovation policy, they can be specified as follows:

A principle of homeostatic nature: national and regional innovation safety; macroeconomic stability.

A principle of hierarchical nature: multilevel complementary innovation policy (institutional complementarity, division of competences; addition of organization and self-organization processes).

A principle of nonlinearity: consideration of «natural» aims of the development of subsystems (macroregions, regions, economy managerial subjects); a differentiated monitoring system (for every subsystem - a region, a sector, etc.) and efficiency assessment of state innovation policy followed by the trend correction.

A principle of the closed state (openness): specialization according to innovation process stages, resource-competence complementarity, cooperative and integrative relations (vertical and horizontal), managerial experience spreading, common information space, information-communication management technologies.

A principle of instability: forecasting of the innovation development of the country, regions and external environment, research of the world trends, strategic planning, assessment of risks and threats to the National Innovation System and the Regional Innovation System, research of the state and tendencies of world markets; indirect (nonforced) influence on the choice of the further development pathway for the innovation system to pave.

A principle of dynamic hierarchical nature (emergentism): coordination of innovation policy and interaction of innovation system institutes of all levels promoting creation of new structures at intermediate levels (intercompany, inter-regional).

A principle of observability: logic of state innovation policy formation «from below»; communication (agreement on positions) between innovation system levels and trends of adjacent policies (innovative, scientific and technical, industrial, educational, intellectual property, etc.).

\section{State innovation policy on the basis of the open model of innovation process management}

The empirical sphere, that is actually existing objects (as a rule tangible), processes, phenomena (e.g. households, organizations, their resources, activity instruments and tools), is researched at the microlevel of innovation policy. Macrolevel objects, in their turn, are some kind of a conceptual sphere [17] (aims, preferences, expectations, etc.). In this case, mezolevel objects are a group of ones - the sum total of economy managerial subjects (organizations, industrial complexes, regions, etc.), demonstrating behavior of a group of objects. It is important that mezoeconomic analysis is characterized by the refusal from depersonalized object perception [17].

A peculiarity of macrolevel objects of state policy is their resemblance with systems of the type «environment» [18], as main management tasks at the national level of the innovation system is elaboration and realization of innovation policy and adjacent policy trends: investment policy and industrial, educational, scientific policies, support of small and medium 
business, formation of demand for innovation output, institutional reorganizations.

According to the synergy approach the state role at the macrolevel of innovation policy is important in creating conditions for self-organization processes at mezo- and microlevels. But Knjazeva E. N., Kurdjumov S.P. point out that «a certain portion of chaos, that is a portion of spontaneous self-organization, and a certain part of management, external supervision are necessary for the dynamic development of complex social structures. These two components - self-organization from below and organization from above - must be in balance» [19].

In its turn, this «self-organization from below» with regard to the macrolevel can take place both at the microlevel and at the mezolevel, if self-organizing systems are regions.

State innovation policy at the mezolevel is of special importance because:

First, if the macrolevel creates environment, a possibility of purposeful point management of innovation processes, of local production encouragement, of innovation network designing, etc. arises at the region level. Diffusion, selection of innovations, formation of intercompany relations occur mainly at the regional level.

Second, a mezolevel peculiarity is that it combines characteristics of the environment and management object. On the one hand, a regional level, as well as a macrolevel, produces environment for innovation activity subjects and their self-organization (within the range of their competence). On the other hand, a region is a management object for the macrolevel and gets in self-organization conditions formed by it.

Thus, a special object - a complex spatial-level aggregate of interactions both «subject-object» and «subject-subject» - appears for state innovation policy.

«Pure self-organization» does not seem to be possible in conditions of state management, availability of restriction institutes, compulsion, legality maintenance, etc. (especially under a federal state organization). It would surely be combined with the organization. Every level of a complex innovation system is characterized by internal independent activity. Its natural evolution, as of an object, by means of selforganization may not always correspond to expected, desirable for the community development results. The task of organizing levels is to direct an object (by means of so called fluctuations) to a set aim which takes into account natural evolution needs.

As organization and self-organization processes give rise to higher organization levels, from economic viewpoint, Russian federalism can acquire a new configuration. Implementation of state innovation policy at the mezolevel is carried out by new structures formal network organizations, having competences and machinery of integration and coordination of innovation activity subjects in various regions.

Consequently, a determining principle of innovation policy at the mezolevel must be the principle of the theory of systems «unity via diversity» (systems containing diverse elements are more stable and adaptive to external environment changes). A specific character of Russian mezoeconomic space is in its strong inter-regional differentiation and polarity in the innovation development. This is often considered as a problem and threat to innovation development of the country. Regions aim at strengthening their competitive positions and the best possible advance in comparison with others. Diversity of regional innovation systems contains a development potential if they are considered as the whole, having complementary elements and developing according to co-evolution principles.

\section{Conclusion}

At present the development of disintegration processes of mezoeconomic space is typical in Russia. According to the research [20], there are tendencies to change inter-regional cooperation interactions to competitive ones in conditions of limited investment resources, dominance of commercial-mediatory interactions over production ones, increase of monopolistic aspirations in economically developed regions and opportunism of different interests.

Thus, an important task of innovation policy at the mezolevel is to develop more complex organizations and structures by means of integration of various parts of the system (regions) developing at a different pace, but in one evolution integrity. According to Knjazeva E. N., Kurdjumov S.P. «to develop a complex organization it is necessary to connect coherently substructures inside it, synchronize their evolution pace...Therefore, development of the structures which are integrated in a complex one is accelerated. Fast developing structures «attract» slowly developing ones» [19]. As a result, management in the frame of innovation policy is not based on hierarchal structures any longer (a cybernetic approach) and a transition to heterogeneous space selforganization (a synergy approach) is carried out.

\section{Acknowledgment}

The results presented in this work were obtained with the assistance from Russian Foundation for Humanities (project № 16-02-00492 «Development of a model of cross-regional cooperation in innovative activities»).

\section{References}

1. B. Rasmussen, Pharm. Ind. Project Work. Pap. Serie, 31, (2007)

2. H. W. Chesbrough, W. Vanhaverbeke, J. West, (Oxford University Press, 2006).

3. U. Lichtenthaler, IEEE transact. on engine. manag., 1, (2008)

4. J. Wit, B. Dankbaar, G. Vissers, Jour. of Business Chem., 1, (2007)

5. P. Altmann, C. Lee, DiVA Acad. Archive On-line

6. R\&D management in Russian companies: national report (2011) 
7. J. F. Christensen, M. H. Olesen, J. S. Kjar, Research Policy, 34(10), (2005)

8. E. N. Knjazeva, S.P. Kurdjumov, Syner. and soc. manag., 351, (1998)

9. S.H. Karpenkov, Higher School (2003)

10. N.N. Moiseev, Science, (1987)

11. R. Rothwell, Internat. Market. Review, 1, (1994)

12. E.N. Akerman, O.V. Kozlovskaya, (Tomsk Polytech. Univer. Publish, 2010)

13. L.P. Yevstigneeva, R.N. Yevstigneev, (IE RAS, 2007)

14. V. I. Arshinov, V. G. Budanov, (Instit. of Philos. RAS, 2005)

15. V.E. Lepsky, «Kogito-Centre» (2010)

16. N.A. Telnova, Volgograd State Univer. jour. Philos. Soc. Technol., 5, (2006)

17. G.B. Kleiner, Econ. jour. Rostov State Univer., 2, (2003)

18. N.V. Yakovleva, Econ. Scien. of Pres. Day Russia, 4, (2009)

19. E. N. Knjazeva, S.P. Kurdjumov, Site of S.P. Kurdjumov

20. R.S. Mirzoev, Jour. Volgograd State Univer., 1(18), (2011)

21. A.J. Berkhout, D. Hartmann, P. Duin, R. Ortt, Technol. Manag., 3/4, (2006)

22. H.W. Chesbrough, M. M. Appleyard, California manag. Review, 1, (2007)

23. L. Dahlander, D.M. Gann, Research Policy, 39, (2010)

24. O. Gassmann, E. Enkel, H. Chesbrough, R\&D Manag., 40(3) (2010)

25. S.J. Herstad, C. Bloch, B. Ebersberger, E. Velde, Scien. and Pub. Policy, 37(2), (2010)

26. U. Lichtenthaler, Technovation, 30 (2010)

27. P. Teirlinck, A. Spithoven, Region. Stud., 42(5), (2008)

28. P. Trott, D. Hartmann, Internat. Jour. of innov. Manag., 4, (2009)

29. V. Vrande, J. Jong, W. Vanhaverbeke, M. Rochemont, Technovation, 29, (2009)

30. J. Wit, B. Dankbaar, G. Vissers, Jour. of Business Chem., 1, (2007) 